\title{
АНАЛИЗ ЭФФЕКТИВНОСТИ ИСПОЛЬЗОВАНИЯ ВНЕОБОРОТНЫХ АКТИВОВ ОРГАНИЗАЦИИ
}

\author{
М. А. Любимская \\ Московский гуманитарный университет
}

Аннотация: В статье отмечено, что роль внеоборотных активов в организациях неоспорима и многие сталкиваются с необходимостью объективной оценки своих активов. В статье рассматриваются теоретические и практические вопросы анализа состояния и эффективности использова-

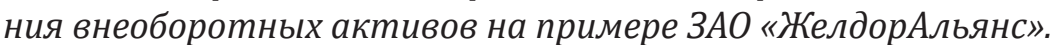

Текст доклада автора на Общероссийской (национальной) научной конференции «Моисеевские чтения. Культура и гуманитарные проблемы современной цивилизации», которая состоялась 4-5 марта 2020 2. в Московском гуманитарном университете.

Ключевые слова: бухгалтерский баланс; внеоборотный актив; нематериальный актив; имущественное состояние; экономическая эффективность

\section{AN ANALYSIS OF THE EFFICIENCY OF A COMPANY'S USAGE OF ITS FIXED ASSETS}

\author{
M. A. Lyubimskaya \\ Moscow University for the Humanities
}

Abstract: The paper notes that fixed assets undoubtedly play a part in companies, and many of them face the need for an objective assessment of their assets. The author considers the theoretical and practical issues of the analysis of the condition and usage of fixed assets in CJSC "ZheldorAlians".

The text of the author's speech at the All-Russian (National) Scientific Confer-ence "Moiseev's Readings. The Culture and Humanitarian Issues of Modern Civilisa-tion", which was held at Moscow University for the Humanities on 4-5 March, 2020.

Keywords: analysis; balance sheet fixed asset; intanqible asset; state of property; economic efficiency

Ведение деятельности предприятия любому руководителю хочется производить с наименьшими потерями и с наибольшей прибылью. Но одной из основных проблем обеспечение эффективности стабильного экономического роста современной организации как раз является неэффективная политика управления внеоборотными активами (Селезнева, 2017: 215).

Внеоборотные активы требуют постоянного контроля и управления ими и особенно важными, в этих условиях, являются анализ внеоборотных активов. Внеоборотные активы имеют существенную долю в балансе организации рисунок 1.

$$
\text { Можно отметить, }
$$

что управление активами является одним из главных направлений в деятельности

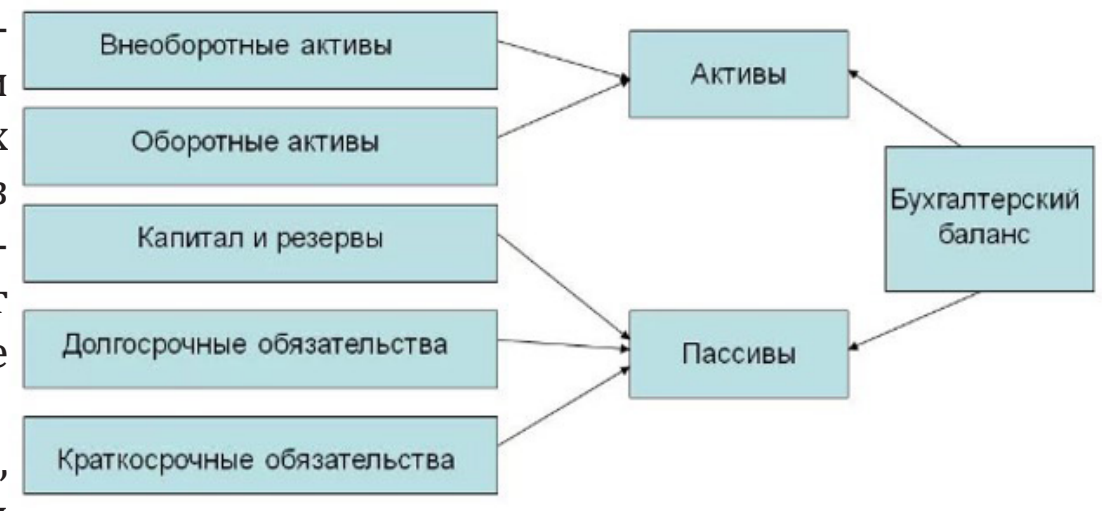

Рис. 1. Место внеоборотных активов в структуре бухгалтерского баланса. 
организации. Как оборотные, так и внеоборотные активы являются неотъемлемой частью производственной деятельности. От того, как организован процесс производства (как сформированы внеоборотные активы) будет зависеть деятельность организации и получение прибыли.

Многие авторы дают разные трактовки понятия внеоборотные активы, мы остановимся на понятии, которое дает Н. Н. Селезнева: «Внеоборотные активы это набор инструментов, с помощью которых современные организации могут получать прибыль и вести финансово-хозяйственную деятельность» (Селезнева, 2017: 217). Состав внеоборотных активов представлен на рисунке 2.

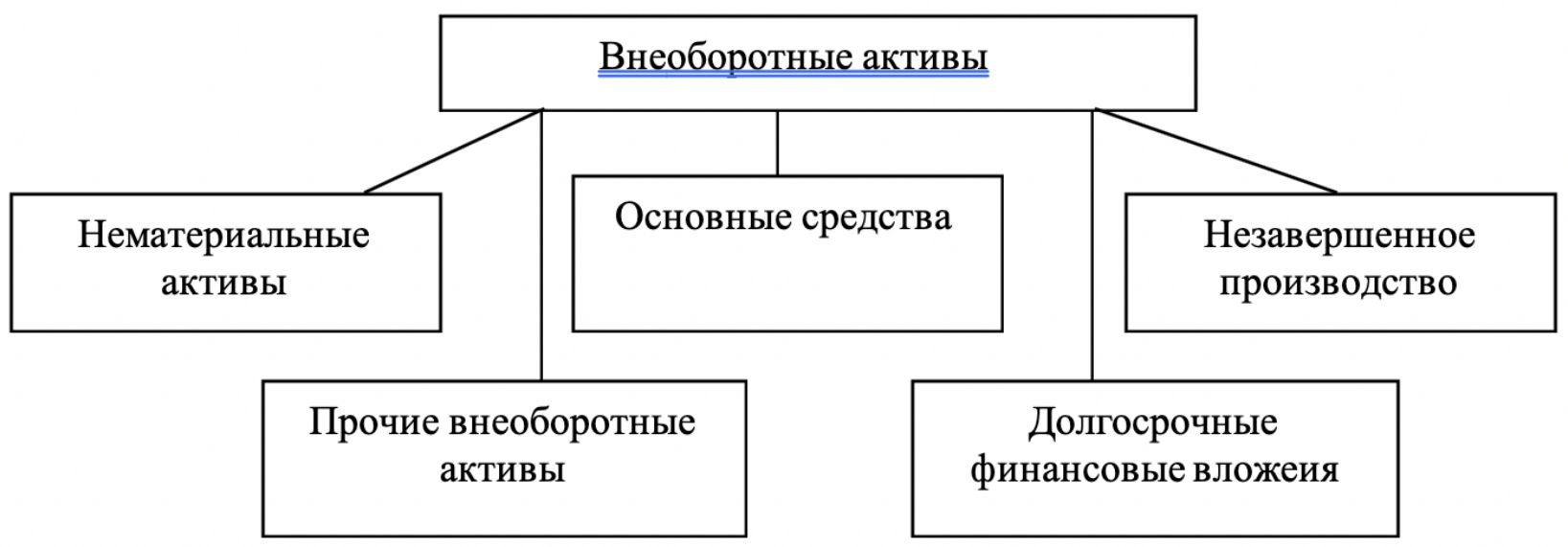

Рис. 2. Состав внеоборотных активов.

По данным рисунка 2 видно, что к внеоборотным активам относятся основные средства, нематериальные активы, не менее важный показатель финансовые вложения и прочие внеоборотные активы (имущество, которое еще нельзя отнести к основным средствам).

Классификация внеоборотных активов представлена на рисунке 3.

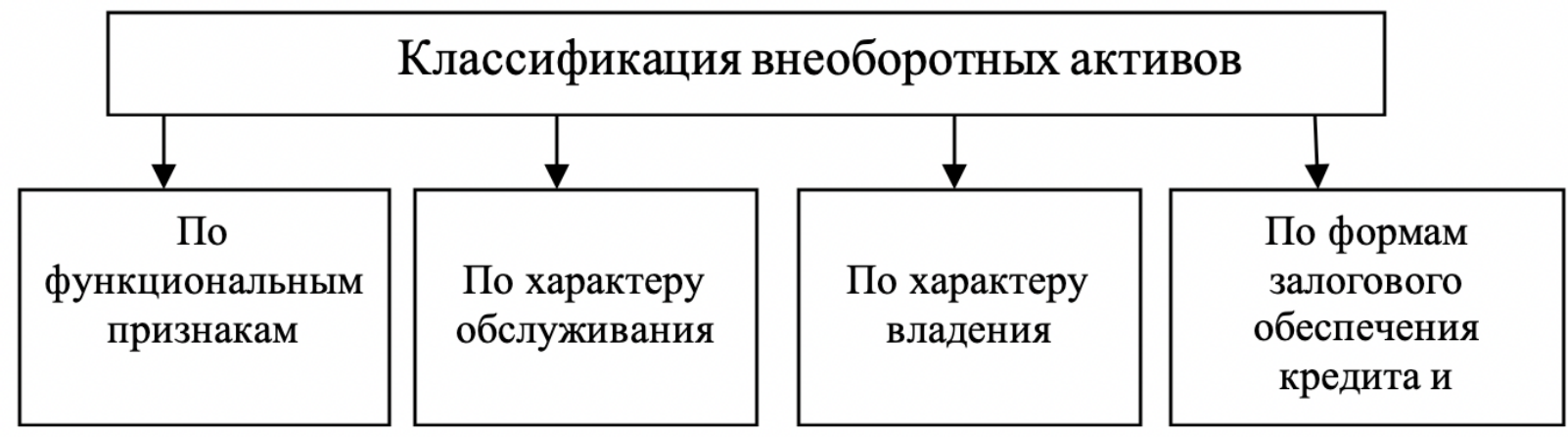

Рис. 3. Классификация внеоборотных активов.

Источниками данных для проведения анализа внеоборотных активов являются:

- $\quad$ бухгалтерский баланс (форма 1), который содержит данные для анализа статей баланса (вертикальный и горизонтальный анализ внеоборотных активов);

- $\quad$ отчет о финансовых результатах (форма 2), откуда берется информация о 
величинах, по отношению к которым рассчитываются коэффициенты и показатели эффективности использования внеоборотных активов;

- $\quad$ приложения к отчету о финансовых результатах (форма 5), где происходит расшифровка информации о внеоборотных активах, которые представлены группами и видами (там же: 147).

Также используются такие данные как:

- статотчетности в которых происходит расшифровка состава и движения основных средств в составе внеоборотных активов;

- бухгалтерских учетных регистров;

- нормативно-справочная литература, учетная политика, положения (Пласкова, 2018: 115).

Цель анализа внеоборотных активов состоит в нахождении резерва эффективности использования внеоборотных активов. Анализ внеоборотных активов является многосторонним анализом и позволяет оценить:

- структуру и текущее состояние внеоборотных активов;

- уровень эффективности их использования внеоборотных активов;

- динамику внеоборотных активов;

— осуществить прогноз внеоборотных активов (там же: 117).

Далее необходим выбор оптимальной модели эффективности использования внеоборотных активов, что будет являться результатом анализа.

Также в процессе анализа внеоборотных активов осуществляется:

- оценка уровня обеспеченности собственным капиталом организации внеоборотные активы;

- оценка изменения стоимости внеоборотных активов в структуре баланса (итог баланса);

- оценка показателей эффективности использования основных средств (фондоотдача, фондоемкость, фондовооруженность, фондообеспеченность);

- оценка показателей изменения во времени и характеризуют эффективность использования внеоборотных активов;

- оценка динамики затрат на поддержание основных средств и отражения их на себестоимости продукции (Залилова, 2016: 37).

В процессе анализа необходимо рассчитывать абсолютные и относительные показатели (величины) которые дают оценку текущего состояния, помогают осуществить прогноз на перспективу, а также выявить причины отклонения данных по внеоборотным активам организации, так как ведение деятельности предприятия должно сопровождаться меньшими потерями и большей прибылью.

Последовательность проведения анализа внеоборотных активов:

- $\quad$ сбор данных активов и систематизация их в таблицах, которые помогают выявить отклонения;

- нахождение и расчет показателей внеоборотных активов, выявление отклонений;

- $\quad$ определение оптимальных показателей внеборотных активов для дальнейшей работы организации направленной на получение прибыли (Селезнева, 2017: 215). 
Оценить уровень эффективности использования внеоборотных активов можно с помощью таких показателей как:

- показатель оборачиваемости внеоборотных активов (отношение выручки от реализации продукции к среднегодовой стоимости внеоборотных активов). Этот показатель дает понять, как быстро оборачивается немобильное имущество предприятия;

- период оборота внеоборотных активов в днях. Показатель, отражающий уровень эксплуатации внеоборотных активов (основных средств) (среднегодовой стоимости внеоборотных активов к выручке от реализации продукции *100);

- рентабельность внеоборотных активов показывает рост или снижение размера прибыли и рассчитывается как отношение прибыли к среднегодовой стоимости внеоборотных активов (Залилова, 2016: 38).

Далее проведем анализ внеоборотных активов ЗАО «ЖелдорАльянс», которое предоставляет услуги по перевозкам в городе Москва.

Первоначальным при анализе внеоборотных активов является определение структуры и динамики активов.

Динамику и структуру внеоборотных активов представим в таблице 1 и диаграмме.

Таблища 1. Динамика и структура внеоборотных активов ЗАО «ЖелдорАльянс», 2016-2018 г2.

\begin{tabular}{|l|c|c|c|c|c|c|c|c|}
\hline \multirow{2}{*}{$\begin{array}{l}\text { Наименование } \\
\text { показателя }\end{array}$} & \multicolumn{2}{|c|}{2016 год } & \multicolumn{2}{c|}{2017 год } & \multicolumn{2}{c|}{2018 год } & \multicolumn{2}{c|}{ Отклонение } \\
\cline { 2 - 9 } & $\begin{array}{c}\text { Сум. } \\
\text { руб. }\end{array}$ & $\begin{array}{c}\text { \% к } \\
\text { итогу }\end{array}$ & $\begin{array}{c}\text { Сумма, } \\
\text { тыс. } \\
\text { руб. }\end{array}$ & $\begin{array}{c}\text { \% к } \\
\text { итогу }\end{array}$ & $\begin{array}{c}\text { Сумма, } \\
\text { тыс. } \\
\text { руб. }\end{array}$ & $\begin{array}{c}\% \text { к } \\
\text { итогу }\end{array}$ & $\begin{array}{c}\text { Сумма, } \\
\text { тыс. руб. }\end{array}$ & $\begin{array}{c}\% \text { к } \\
\text { итогу }\end{array}$ \\
\hline $\begin{array}{l}\text { Внеоборотные } \\
\text { активы всего }\end{array}$ & 124599 & 100 & 91516 & 100 & 325985 & 100 & 201386 & 0 \\
\hline $\begin{array}{l}\text { Основные } \\
\text { средства }\end{array}$ & 123854 & 99,4 & 91516 & 100 & 318399 & 97,67 & 194545 & $-1,7$ \\
\hline $\begin{array}{l}\text { Финансовые } \\
\text { вложения }\end{array}$ & - & - & - & - & 7299 & 2,239 & 7299 & 2,24 \\
\hline $\begin{array}{l}\text { Отложенные } \\
\text { налоговые } \\
\text { активы }\end{array}$ & 745 & 0,598 & - & - & 287 & 0,088 & -458 & $-0,5$ \\
\hline
\end{tabular}

По данным таблицы 1, внеоборотные активы увеличиваются на 201386 тыс. руб. или более чем в 2 раза, это произошло в большей степени за счет увеличения основных средств на сумму 194545 тыс. руб. к 2016 г.

Происходит обновление основных средств, а именно приобретены в лизинг транспортные средства на сумму в 2016 г. 9787 тыс. руб., в 2017 г. - на 5380 тыс. руб. и в 2018 г. - на сумму 2630304 тыс. руб.

Собственные основные средства в ЗАО «ЖелдорАльянс» составили в 2016 г. 114067 тыс. руб., в 2017 г. - 86136 тыс. руб. и в 2018 г. - 55095 тыс. руб. и мы видим, 
что к 2018 году их величина снижается на 58972 тыс. руб. по отношению к 2016 г. Можно отметить, что по мере износа, стоимость основных средств уменьшается.

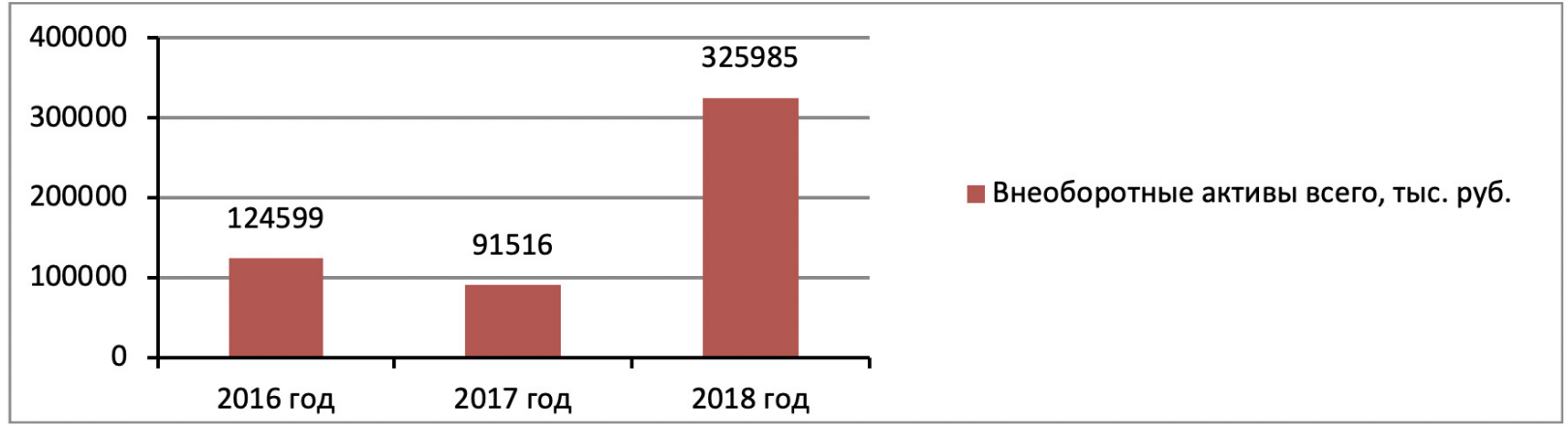

Диаграмма. Динамика внеоборотных активов ЗАО «ЖелдорАльянс», 2016-2018 г2.

Далее, рассматривая структуру внеоборотных активов, видим, что наибольший удельный вес занимают основные средства (99,4\% в 2016 г., 100\% в 2017 г. и 97,67\% в 2018 г.). Отложенные налоговые активы $3 А 0$ «ЖелдорАльянс» - это отсроченный налогнаприбыль,которыйуменьшаетразмерплатежей,иегосуммав2016г.составила 745 тыс. руб., в 2018 г. - 287 тыс. руб. Уменьшение обязательных перечислений связано с расхождениями между бухучетом и нормами, закрепленными в НК РФ. Напротив, финансовые вложения ЗАО «ЖелдорАльянс» увеличились на 7299 тыс. руб. или на 2,24\%, это говорит о вложении свободных денежных средств и прочих ресурсов в активы, не связанные с основной деятельностью ЗАО «ЖелдорАльянс», которое осуществляет услуги по перевозкам.

Анализ эффективности использования внеоборотных активов рассмотрим на материалах ЗАО «ЖелдорАльянс» за 2016-2018 год (таблица 2). Такой анализ даёт возможность охарактеризовать работу ЗАО «ЖелдорАльянс», а также рассчитать отклонения в сравнении с базисными периодами.

Таблица 2. Показатели эффективности использования внеоборотных активов ЗАО «ЖелдорАльянс» 2016-2018 г2.

\begin{tabular}{|c|c|c|c|c|c|}
\hline \multirow{2}{*}{ Показатель } & \multirow{2}{*}{2016 год } & \multirow{2}{*}{2017 год } & \multirow{2}{*}{2018 год } & \multicolumn{2}{|c|}{ Отклонения 2018 от } \\
\hline & & & & 2016 года & 2017 года \\
\hline Основные средства, тыс. руб. & 123854 & 91516 & 318399 & 194545 & 226883 \\
\hline Внеоборотные активы, тыс. руб. & 124599 & 91516 & 325985 & 201386 & 234469 \\
\hline Выручка, тыс. руб. & 138089 & 117422 & 446364 & 308275 & 328942 \\
\hline Чистая прибыль, тыс. руб. & 1437 & 5111 & 4089 & 2652 & -1022 \\
\hline $\begin{array}{l}\text { Среднегодовая } \\
\text { работников, чел. }\end{array}$ & 86 & 88 & 88 & 2 & 0 \\
\hline \multicolumn{6}{|c|}{ Основные средства: } \\
\hline Фондоотдача, коэф. & 1,11 & 1,28 & 1,4 & 0,29 & 0,12 \\
\hline Фондоемкость, коэфф. & 0,9 & 0,78 & 0,71 & $-0,2$ & $-0,1$ \\
\hline Фондорентабельность, \% & 1,16 & 5,58 & 1,28 & 0,12 & $-4,3$ \\
\hline Фондовооруженность, коэфф. & 1440 & 1040 & 3618 & 2178 & 2578 \\
\hline \multicolumn{6}{|c|}{ Внеоборотные активы (ВНА): } \\
\hline Оборачиваемость ВНА, коэфф & 1,11 & 1,28 & 1,37 & 0,26 & 0,09 \\
\hline Рентабельность ВНА, \% & 1,15 & 5,58 & 1,25 & 0,1 & $-4,3$ \\
\hline Период оборота ВНА, дней & 324,8 & 281 & 263 & -62 & -18 \\
\hline
\end{tabular}


Таким образом, внеоборотные активы являются разновидность имущества ЗАО «ЖелдорАльянс». Эффективность использования внеоборотных активов играет важную роль для нормального функционирования и воздействует на эффективность работы ЗАО «ЖелдорАльянс» в целом.

Фондоотдача за исследуемый период выросла на 0,12 и коэффициент достиг 1,4 пункта, рост вызван сильным увеличением выручки на 328942 тыс. руб. по отношению к 2016 г. Так если по полученным расчетам показатель фондоотдчи увеличивается, то можно говорить об эффективности их использования в ЗАО «ЖелдорАльянс». По нормативным значениям, если фондоотдача (Фо) > 1, то основные средства используются эффективно. Коэффициент фондоемкости снизился и достиг 0,71 пункта в 2018 г., а снижение фондоемкости свидетельствует о повышении эффективности использования основных средств.

Наблюдается значительный рост рентабельности основных средств, вызванный подъемом величины чистой прибыли, которая увеличилась на 2652 тыс. руб. (в 2,8 раза). При увеличении данного показателя, принято считать, что основные средства используются эффективно.

Коэффициент фондовооруженности увеличился, что можно говорить о росте производительности труда персонала и трудоемкости в ЗАО «ЖелдорАльянс», оказывающее услуги по перевозкам. Если прирост прибыли превысил прирост основных средств за исследуемый период, то использование основных средств эффективно, что и происходит в ЗАО «ЖелдорАльянс».

По рассчитанным показателям исследуемого предприятия можно сделать вывод, что основные средства в составе внеоборотных активах 3 АО «ЖелдорАльянс» используются эффективно, а эффективность использования основных средств играет важное значение для развития деятельности $3 А 0$ «ЖелдорАльянс». Так как увеличивается экономический потенциал и возможности, повышается технический уровень деятельности, увеличиваются темпы роста производительности труда и улучшается качество услуг по перевозкам.

Коэффициент оборачиваемости внеоборотных активов показывает скорость оборота немобильных активов за анализируемый период. В данном случае он увеличился по сравнению с 2016 г., что является положительной тенденцией. Увеличение данного коэффициента означает насколько правильно ЗАО «ЖелдорАльянс» применяет имеющиеся у нее ресурсы. Показатель рентабельности внеоборотных активов это означает, что средства организация использует эффективно, хотя снижение рентабельности логично и оправдано, если ЗАО «ЖелдорАльянс» будет внедрять новые технологии и оказывать «новые» услуги по перевозкам. Период оборота внеоборотных активов показывает, чем ниже соответствующий показатель, тем более эффективным оценивается управление бизнесом.

К мероприятиям по повышению эффективности использования внеоборотных активов можно отнести поддерживание положительной тенденции таких показателей, как: снижение фондоемкости, повышение фондоотдачи, так как повышение фондоотдачи свидетельствует о повышении эффективности использования основных средств. Снижение фондоемкости показывает, что происходит увеличение мощности при оказании услуг, а также увеличение эффективности 
использования основных средств. Внеоборотные активы требуют инвестиций, поэтому источниками их приобретения должен быть в основном собственный капитал и частично заемные средства. Поддержание положительной динамики данных показателей играет благоприятную роль в увеличении чистой прибыли и росте общей рентабельности деятельности $3 А О$ «ЖелдорАльянс».

\section{СПИСОК ЛИТЕРАТУРЫ}

Залилова, 3. А. (2016) Применение статистических методов для анализа // Актуальные вопросы бухгалтерского учета, статистики и информационных технологий: сборник научных статей. Уфа : Башкирский государственный аграрный университет. С. 37-39.

Пласкова, Н. С. 2018) Экономический анализ: стратегический и текущий аспекты, российская и зарубежная практик. М. : Московская финансово-промышленная академия. 426 с.

Селезнева, Н. Н. (2017) Финансовый анализ. Управление финансами : учебное пособие для вузов. М. : ЮНИТИ-ДАНА. 639 с.

Дата поступления: 30.03.2020 г.

Любимская Мария Алексеевна - студентка бакалавриата направления «Бухгалтерский учет, анализ и аудит» Московского гуманитарного университета. Адрес: 111395, Россия, г. Москва, ул. Юности, д. 5. Тел. +7 (917) 523-48-78. Эл. адрес: lyubimskaya_mash@mail.ru

Lyubimskaya Mariya Alekseyevna, Student, academic programme "Accounting, Analysis and Audit", Moscow University for the Humanities. Postal address: 5, Yunosti St., Moscow, Russian Federation, 111395. Tel. +79175234878. E-mail: lyubimskaya_mash@ mail.ru

\section{Для цитирования:}

Любимская М. А. Анализ эффективности использования внеоборотных активов организации // Научные труды Московского гуманитарного университета. 2020. №2. C. 36-42. DOI: 10.17805/trudy.2020.2.7 